\title{
Effect of meteorological factors on the seasonal prevalence of dengue vectors in upland hilly and lowland Terai regions of Nepal
}

Reshma Tuladhar ${ }^{1,2^{*}}$ D, Anjana Singh ${ }^{1}$, Megha Raj Banjara ${ }^{1}$, Ishan Gautam ${ }^{3}$, Meghnath Dhimal ${ }^{4}$, Ajit Varma ${ }^{2}$ and Devendra Kumar Choudhary ${ }^{2 *}$

\begin{abstract}
Background: The expansion of dengue vectors from lowland plains to the upland hilly regions of Nepal suggests the likelihood of increased risk of dengue. Our objective was to assess the effects of meteorological variables on vector indices and populations of dengue vectors in two different ecological regions of Nepal. An entomological survey was conducted in Kathmandu and Lalitpur (upland) and Chitwan (lowland) of Nepal in three different seasons from July 2015 to May 2016. The effect of meteorological variables on vector indices (house index, container index and Breteau index) and Aedes spp. population abundance was analyzed. A gamma regression was used to fit the models for vector indices and a negative binomial regression was used to model Aedes spp. population abundance.

Results: Monsoon season showed higher values for vector indices and vector populations compared to postmonsoon and pre-monsoon. Overall, the factor temperature-rainfall effect had a more significant influence on vector indices compared to relative humidity. The regression models showed that relative humidity has a greater impact in Chitwan than in Kathmandu. Variation was observed in the effect of predictor variables on Aedes aegypti and Ae. albopictus abundance.

Conclusions: Temperature and rainfall contribute to the vector indices in the upland hilly region while relative humidity contributes in the lowland plains. Since vector prevalence is not only linked to meteorological factors, other factors such as water storage practices, waste disposal, sanitary conditions and vector control strategy should also be considered. We recommend strengthening and scaling up dengue vector surveillance and control programmes for monsoon season in both upland and lowland regions in Nepal.
\end{abstract}

Keywords: Aedes aegypti, Aedes albopictus, Vector indices, Temperature, Rainfall, Relative humidity

\section{Background}

Dengue is an emerging health problem in Nepal which is caused by dengue virus (DENV) and is transmitted to humans mainly by Aedes aegypti and Ae. albopictus mosquitoes. An estimated half of the world population is at risk of dengue with tropical and sub-tropical regions being most vulnerable [1]. It has been calculated that 390

\footnotetext{
* Correspondence: resutu@gmail.com; dkchoudhary1@amity.edu

${ }^{1}$ Central Department of Microbiology, Tribhuvan University, Kathmandu, Nepal

${ }^{2}$ Amity Institute of Microbial Technology, Amity University, Noida, UP, India Full list of author information is available at the end of the article
}

million dengue infections occur per year, of which 96 million manifest as severe [2]. Dengue has become a major public health concern due to its rapid expansion with epidemics being confirmed in 128 countries, including those in Southeast Asia, the Americas, Africa and the western Pacific and Mediterranean regions [3, 4].

Dengue was first reported in Nepal in 2004 from Chitwan District, while the first outbreak occurred in 2006 with confirmed cases from nine districts of the lowland region, also known as Terai in Nepal $[5,6]$. Following the 2006 outbreak, dengue cases were reported

(C) The Author(s). 2019 Open Access This article is distributed under the terms of the Creative Commons Attribution 4.0 International License (http://creativecommons.org/licenses/by/4.0/), which permits unrestricted use, distribution, and 
every year. The next major outbreak occurred in 2010 with 917 cases including five deaths that affected 12 districts of central and western Nepal [7]. Subsequent large outbreaks in the years 2013 and 2016 resulted in 683 cases from 15 districts and 1527 cases from 30 districts, respectively [8]. The periodic outbreaks together with the expansion of dengue affected districts suggest a perpetual threat of dengue in the country.

Previously, dengue cases were reported only from the warmer lowland regions of Nepal. However, the first case of dengue in a patient from Kathmandu (upland region) without a recent history of travel to a dengue-affected area in 2010 [9] was an indication that the upland hilly region of Nepal is also vulnerable to dengue. This warning was supported by a report of finding of the primary vector Ae. aegypti for the first time in Kathmandu in 2009 [10] and by later studies in 2014 $[11,12]$. Earlier entomological investigation had reported the presence of secondary vector Ae. albopictus in Nepal and ascertained that Ae. aegypti did not exist here [13]. However, stable populations of both vectors have already been established from the lowlands to the middle mountain region at an altitude of $1310 \mathrm{~m}$ [14]. Thus, expansion of the geographical range of dengue can be attributed to the spread of Ae. aegypti [15].

Assumptions have been made that the increase in incidence of vector-borne disease like dengue is linked to the climate change as a consequence of global warming [16-18]. Temperature, rainfall and humidity are considered important factors for the survival and development of vectors and the transmission rates of vector-borne pathogens $[19,20]$. While warmer temperatures facilitate the development of mosquito and viral replication [21], adequate rainfall and humidity affect the breeding habitats and survival of vectors, resulting in increased vector populations [22].

The magnitude and geographical distribution of vector populations have been made based on the calculation of vector indices and container habitats [23]. Many studies have focused on larval indices to predict the risk and transmission of dengue [24-26]. The vector indices considered in this research were house index (HI), container index (CI) and Breteau index (BI). We studied larval indices rather than adult population due to collection of adults being both challenging and labor-intensive. Furthermore, dispersal and translocation of adult populations by various means of transportation may provide inaccurate data.

There are a few published studies on seasonal abundance of Aedes vectors in Nepal [12, 14]; however, the statistical relationships between vector indices and meteorological variables have not been studied. The relationship between meteorological variables and mosquito abundance can provide important information in determining the disease risk. Therefore, this study was conducted to investigate population dynamics of Aedes vectors, their species composition, and their association with meteorological variables in two different ecological regions of Nepal.

\section{Methods}

\section{Study area}

Two ecologically different areas of Nepal were selected for this study (Fig. 1). Kathmandu Valley represents an upland hilly region and Chitwan District represents a lowland Terai region of the country. Situated in the central Nepal, Kathmandu Valley has an approximate elevation of $1310 \mathrm{~m}$ above mean sea level (masl) and is characterized by a warm temperate climate. The two districts selected from this valley for sample collections were Kathmandu and Lalitpur municipalities. Chitwan District, situated in the subtropical inner Terai belt of Nepal with an elevation of 415 masl represents lowland.

\section{Data collection}

An entomological survey was carried out in three seasons from July 2015 to May 2016 to determine the variation in the abundance of the vector populations in different seasons. The period from July to September

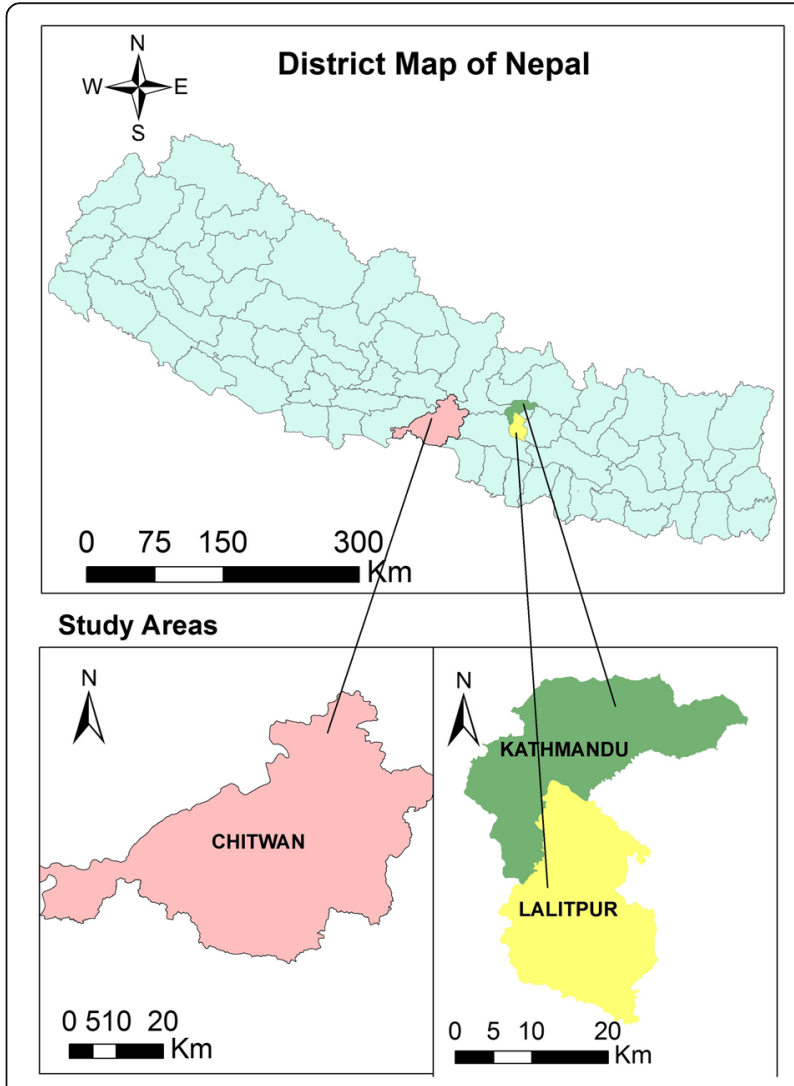

Fig. 1 Study areas 
was considered monsoon, October to December as post-monsoon and March to May as pre-monsoon [27]. Monsoon and pre-monsoon are warmer seasons compared to post-monsoon (Table 1).

We selected 10 locations each from Kathmandu and Chitwan districts, and 9 locations from Lalitpur District for the vector survey. From each district, 100 house premises were inspected for Aedes larvae from potential water-holding containers around the house (outdoor). Types of containers were recorded and the container preferences of Aedes vector breeding were assessed by calculating the breeding preferences ratio (BPR) which is defined as the ratio of number of containers infested (positive) with larvae to the number of water-holding containers examined [28]. The water-holding containers with immature Aedes mosquitoes (larvae) were considered as positive containers. The vector indices considered in the survey were: house index (HI) (percentage of houses with containers positive for Aedes larvae); container index $(\mathrm{CI})$ (percentage of water-holding containers infested with larvae); and Breteau index (BI) (number of positive containers per 100 houses inspected) [23]. These indices were considered in order to assess the prevalence of Aedes vectors.

Daily records of rainfall $(\mathrm{mm})$, relative humidity (\%), maximum temperature $\left({ }^{\circ} \mathrm{C}\right)$ and minimum temperature $\left({ }^{\circ} \mathrm{C}\right)$ from the weather station located $<10 \mathrm{~km}$ from house inspected in the lowland and $<5 \mathrm{~km}$ from house inspected in upland (hills) were obtained from the Department of Hydrology and Meteorology, Kathmandu.

\section{Statistical analysis}

Vector indices (HI, CI and BI) and Aedes spp. numbers were response variables. The factor analysis with principal components analysis (PCA) method was used to reduce the number of variables or to remove the effect of multicollinearity of meteorological variables. TempRain and RelHumidity were two components derived from factor analysis. The predictor variables considered were Kathmandu, Chitwan, monsoon, post-monsoon, TempRain, RelHumidity, K_TempRain, K_RelHumidity, C_TempRain and C_RelHumidity. $\mathrm{K}$ and $\mathrm{C}$ were dummy variables which indicated Kathmandu and Chitwan, respectively, with reference to Lalitpur. Similarly, monsoon and post-monsoon were dummy variables which signified monsoon and post-monsoon, respectively, with reference to pre-monsoon.

Data collection on response variables was cross-sectional in nature although different seasons were considered. Data were based on the sample from households in three different districts. Each household was surveyed enumerated three times to note the response of vector in three different seasons. Data on meteorological predictor variables were also recorded three times. As the response variables, $\mathrm{HI}, \mathrm{CI}$ and $\mathrm{BI}$, are continuous in nature, regression models for count response variables such as a Poisson regression or negative binomial models were not suitable. The repeated sample size was too small to run a generalized linear mixed model (GLMM). The inclusion of interaction terms also prevented its further use since models with interaction terms need a sufficient sample size. The final dataset had only 87 sample observations. Thus, we used generalized linear model (GLM) since it can fit even when the response variables are non-linear in nature and have outliers. The response variables, Ae aegypti and Ae. albopictus numbers, have a count outcome, hence a Poisson or negative binomial model was possible. Since the standard deviation was greater than mean, we used a negative binomial regression for vector abundance.

Some models were fitted with a log-link function in GLM. For this, the response variable must be positive, but $\mathrm{HI}, \mathrm{BI}$ and $\mathrm{CI}$ have some zero values. To avoid this complication, a constant quantity of 1 was added to each of these response variables. The addition of a constant to a variable did not affect the mean and variance of that variable. These variables were then named as HI_1, BI_1 and CI_1. Generalized models were fitted to the latter response variables separately on a given set of meteorological predictor variables along with some dummy variables. Moreover, the models included some interaction terms based on the fitting criteria. The best-fit models were selected and interpreted.

All statistical analyses were conducted using SPSS Statistics software v.21. GraphPad Prism v.7 was used to construct scatter plots and bar diagrams.

Table 1 Average meteorological records in Kathmandu Valley and Chitwan District of Nepal

\begin{tabular}{llllll}
\hline Location & Season & Minimum temperature $\left({ }^{\circ} \mathrm{C}\right)^{\mathrm{a}}$ & ${\text { Maximum temperature }\left({ }^{\circ} \mathrm{C}\right)^{\mathrm{a}}}$ & Rainfall $^{(\mathrm{mm})^{\mathrm{a}}}$ & ${\text { Relative humidity }(\%)^{\mathrm{a}}}$ \\
\hline Kathmandu Valley (hilly region) & Monsoon & $19.6 \pm 0.62$ & $29.33 \pm 0.21$ & $370.7 \pm 157.20$ & $82.3 \pm 1.50$ \\
& Post-monsoon & $9.2 \pm 4.70$ & $23.2 \pm 4.20$ & $22.5 \pm 39.00$ & $79.6 \pm 2.50$ \\
& Pre-monsoon & $13.03 \pm 3.30$ & $27.23 \pm 3.00$ & $106.4 \pm 59.60$ & $66.8 \pm 3.40$ \\
Chitwan District (plain land) & Monsoon & $25.13 \pm 0.47$ & $33.9 \pm 0.52$ & $339.2 \pm 174.75$ & $84.82 \pm 0.45$ \\
& Post-monsoon & $14.1 \pm 5.25$ & $27.6 \pm 4.41$ & $1.4 \pm 2.42$ & $88.5 \pm 4.12$ \\
& Pre-monsoon & $18.3 \pm 3.76$ & $32.7 \pm 2.81$ & $56.7 \pm 50.77$ & $75.1 \pm 3.70$ \\
\hline
\end{tabular}

${ }^{\mathrm{a}}$ Data are average of monthly data of each season \pm standard deviation (SD) 


\section{Results}

A total of 300 houses (100 houses in each location) were surveyed, out of which 64 houses were found to be positive for Aedes breeding containers. Within the premises of houses surveyed, 782 water-holding containers $(n=$ 332 in Kathmandu; $n=277$ in Lalitpur; and $n=173$ in Chitwan) were identified and Aedes larvae was present in 220 water-holding containers $(n=67$ in Kathmandu; $n=100$ in Lalitpur; and $n=53$ in Chitwan). Containers found in each house were recorded to determine the dominant mosquito breeding containers in different locations. Since the survey was conducted in an urban area, breeding habitats found were primarily artificial containers. In terms of number, discarded tire was the dominant breeding container in all three locations. The highest number of discarded tires $(n=92)$ with a presence of Aedes larvae was found in Lalitpur, while the least number $(n=46)$ was found in Chitwan. Containers made of materials like metal and plastic were common breeding habitats (Additional file 1: Table S1). The BPR was observed to be the highest for glass containers (4.9) in Kathmandu, metal containers (1.43) in Lalitpur and metal drum containers (3.16) in Chitwan (Fig. 2).

The vector indices $\mathrm{HI}, \mathrm{CI}$ and $\mathrm{BI}$ were found to be the highest during monsoon season followed by post-monsoon and the lowest during the pre-monsoon season (Table 2). The highest vector indices were recorded in Lalitpur during monsoon season (HI: 21.2; CI: 41.8; BI: 0.1 ) followed by Chitwan (HI: 20.8; CI: 36; BI: 0.05) and Kathmandu (HI: 19.7; CI: 24.3; BI: 0.06). The vector indices values were observed to be the lowest in Chitwan during post-monsoon season (Table 2). Since no water-holding containers were identified in the premises of the houses surveyed in Chitwan during the pre-monsoon season, vector indices were not assessed in this area for this period. HI values were $>5 \%$ during monsoon season and varied between $0.1-5 \%$ during post-monsoon season.

The highest numbers of Aedes larvae were detected during monsoon season (Additional file 2: Figure S1). The average number of Ae. aegypti larvae was higher in the lowland Terai region compared to upland hills where the average number of Ae. albopictus was almost identical in both regions, indicating Ae. aegypti to be the dominant species in lowland (Fig. 3).

A significant positive relationship $(P<0.05)$ between maximum temperature and vector indices was observed from the scatterplot (Fig. 4). Similarly, the correlation of minimum temperature and rainfall with vector indices was nearly identical to the results of maximum temperature in all locations except for $\mathrm{CI}$ in Kathmandu Valley where a poor correlation was observed (Figs. 5 and 6). The strength of the relation of HI and BI with the meteorological variables was comparatively better than CI. Relative humidity showed a significant weak positive correlation with vector indices in Chitwan, but no linear correlation in the hilly regions (Fig. 7). Despite the significant correlation of temperature and rainfall with vector abundance in both ecological regions, relative humidity showed a differential relationship (Fig. 8).

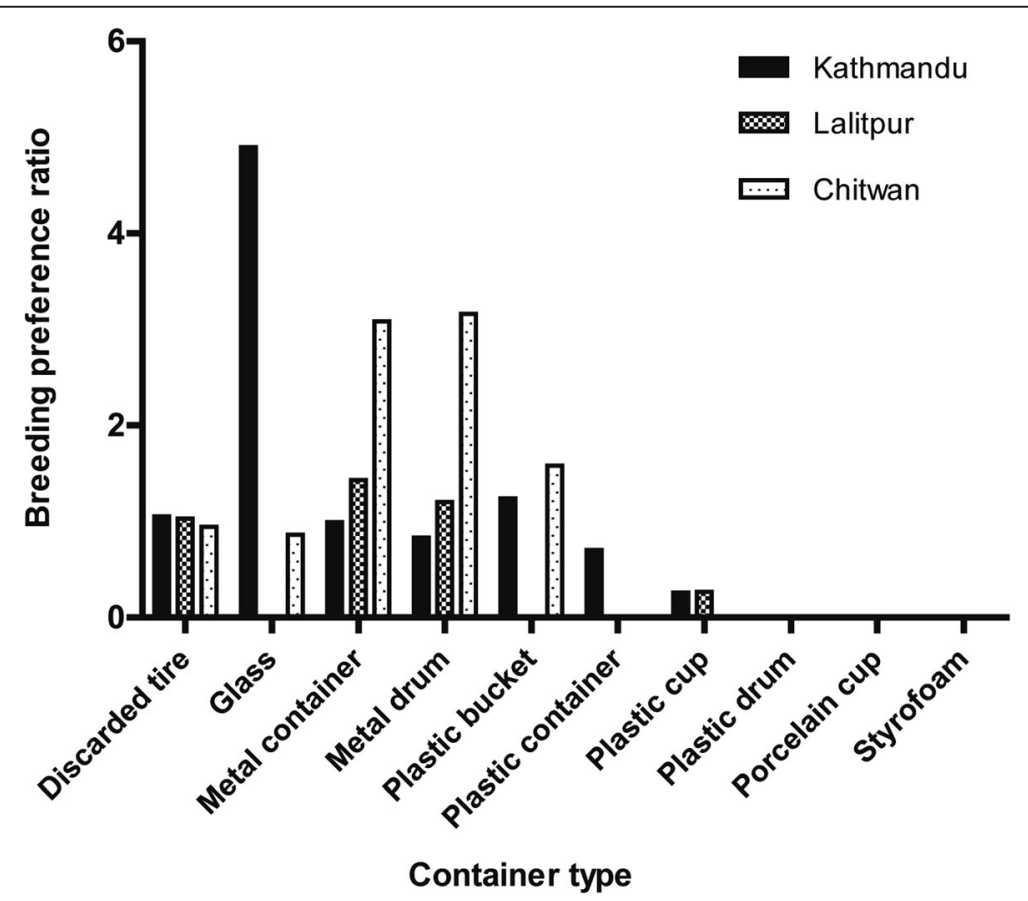

Fig. 2 Breeding preference ratio (BPR) of different containers positive for Aedes vector breeding 
Table 2 Entomological indices $(\mathrm{HI}, \mathrm{Cl}$ and $\mathrm{Bl})$ in study locations at different seasons

\begin{tabular}{|c|c|c|c|c|c|c|c|c|c|c|}
\hline \multirow[t]{2}{*}{ Location } & \multirow[t]{2}{*}{$n$} & \multicolumn{3}{|c|}{ Larval indices in monsoon } & \multicolumn{3}{|c|}{ Larval indices in post-monsoon } & \multicolumn{3}{|c|}{ Larval indices in pre-monsoon } \\
\hline & & $\mathrm{HI}$ & $\mathrm{Cl}$ & $\mathrm{Bl}$ & $\mathrm{HI}$ & $\mathrm{Cl}$ & $\mathrm{Bl}$ & $\overline{\mathrm{HI}}$ & $\mathrm{Cl}$ & $\mathrm{Bl}$ \\
\hline Kathmandu & 10 & 19.7 & 24.3 & 0.06 & 3.02 & 15.20 & 0.0060 & 0.59 & 4.0 & 0.0020 \\
\hline Lalitpur & 9 & 21.2 & 41.8 & 0.10 & 3.00 & 12.06 & 0.0067 & 3.17 & 7.4 & 0.0067 \\
\hline Chitwan & 10 & 20.8 & 36.0 & 0.05 & 2.70 & 11.10 & 0.0030 & - & - & - \\
\hline
\end{tabular}

Abbreviations: $\mathrm{Bl}$ Breteau index, $\mathrm{Cl}$ container index, $\mathrm{HI}$ house index

Some important predictor variables were omitted due to their high multicollinearity effect in the regression models. To keep these variables in the model, a PCA method was adopted. This method created two new predictor variables termed as factors or principal components. Factor 1 was designated as temperature-rainfall effect (TempRain) and factor 2 as relative humidity effect (RelHumidity) (Additional file 3: Table S2). The newly generated variables were not correlated.

Generalized linear models (GLM) were fitted for response variables on given predictor variables along with some dummy variables based on the fitting criteria. Both a deviance test and omnibus test supported that six models Normal (HI_1) with identity link function, Normal (HI_1) with log link function, Gamma regression (HI_1) with identity link function, Gamma (HI_1) with log link function, Tweedle_1.5 (HI_1) with identity link function and Tweedle_1.5 (HI_1) with log link function were well fitted to the data (Additional file 4: Table S3). In order to select best-fit model within the six types of GLM of HI_1, the criteria of lowest value of AIC (or $\mathrm{BIC})$, mean deviance $(-2 \mathrm{LL} / \mathrm{df})$ close to one, and dispersion parameter less than one, were used. Gamma (HI_1) with identity link function and Gamma (HI_1) with log link function were preferred as the best-fit models. Gamma (HI_1) with log link function seemed better than Gamma (HI_1) with identity link function since the former model included five significant predictor

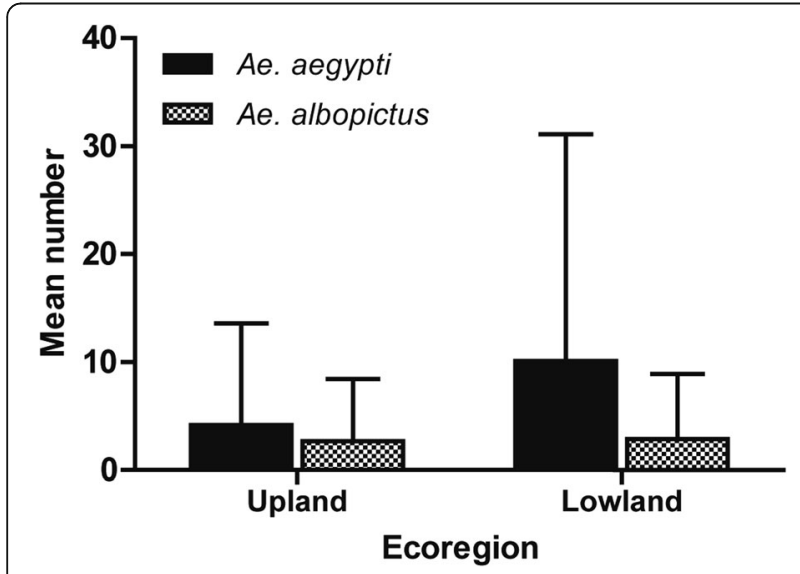

Fig. 3 Comparision of Ae. aegypti and Ae. albopictus number in upland hilly region and lowland Terai region variables compared to the latter model. Hence, Gamma (HI_1) with log link function was further modified such that it contained all the significant predictor variables. Several possible subsets of this model were fitted with the significant predictors. The final model was selected and is listed in Additional file 4: Table S3 (models 7, 8 and 9) and Table 3. Three gamma regression models for HI_1 were selected as they satisfied all the criteria of model fit (Additional file 4: Table S3). Furthermore, they included only significant predictor variables and the coefficients of each of these models were interpreted.

Model 4 included all 10 predictor variables. However, the fitting of the models showed only five of them as highly significant predictors under the Wald Chi-square test $(P<0.05)$ (Table 3$)$. Hence, it did not meet the requirement of only significant predictors from the fitting of gamma regression of HI_1 with log link function. We interpreted the coefficients of the predictors, dummy variables Chitwan and Kathmandu (as location variables) have no influence on HI_1. Similarly, monsoon and post-monsoon (as seasonal variables) have significant consequence. TempRain as main effect, C_TempRain and $\mathrm{K}_{-}$TempRain as interaction effects have insignificant influence on HI_1. RelHumidity, C_ RelHumidity and K_ RelHumidity as main and interaction effects have significant consequence on HI_1.

The partial regression coefficients are expressed in exponential form, i.e. $\exp \left(b_{i}\right)$, so that interpretation is simple and straightforward. Exponential value $>1$ indicated greater effect of the predictor on the response variable and exponential value $<1$ indicated less effect of the predictor on the response variable. Exponential of the zero value of the coefficient is one. When interpreting partial regression coefficients, a negative sign indicates a decrease in the response variable and a positive sign indicates an increase in the response variable per unit increase in a given predictor keeping the remaining predictors constant.

Chitwan $[\exp (-0.470)=0.625]$ and Kathmandu [exp $(-0.279)=0.756]$ have values $<1$. This means that Lalitpur could have a greater value of HI_1 on average compared to Chitwan and Kathmandu. Moreover, RelHumidity [exp $(-0.540)=0.583], C_{-}$TempRain [exp $(-0.096)=0.908]$ and K_TempRain $[\exp (-0.158)=$ 0.854 ] showed significantly lower effect on HI_1 keeping 


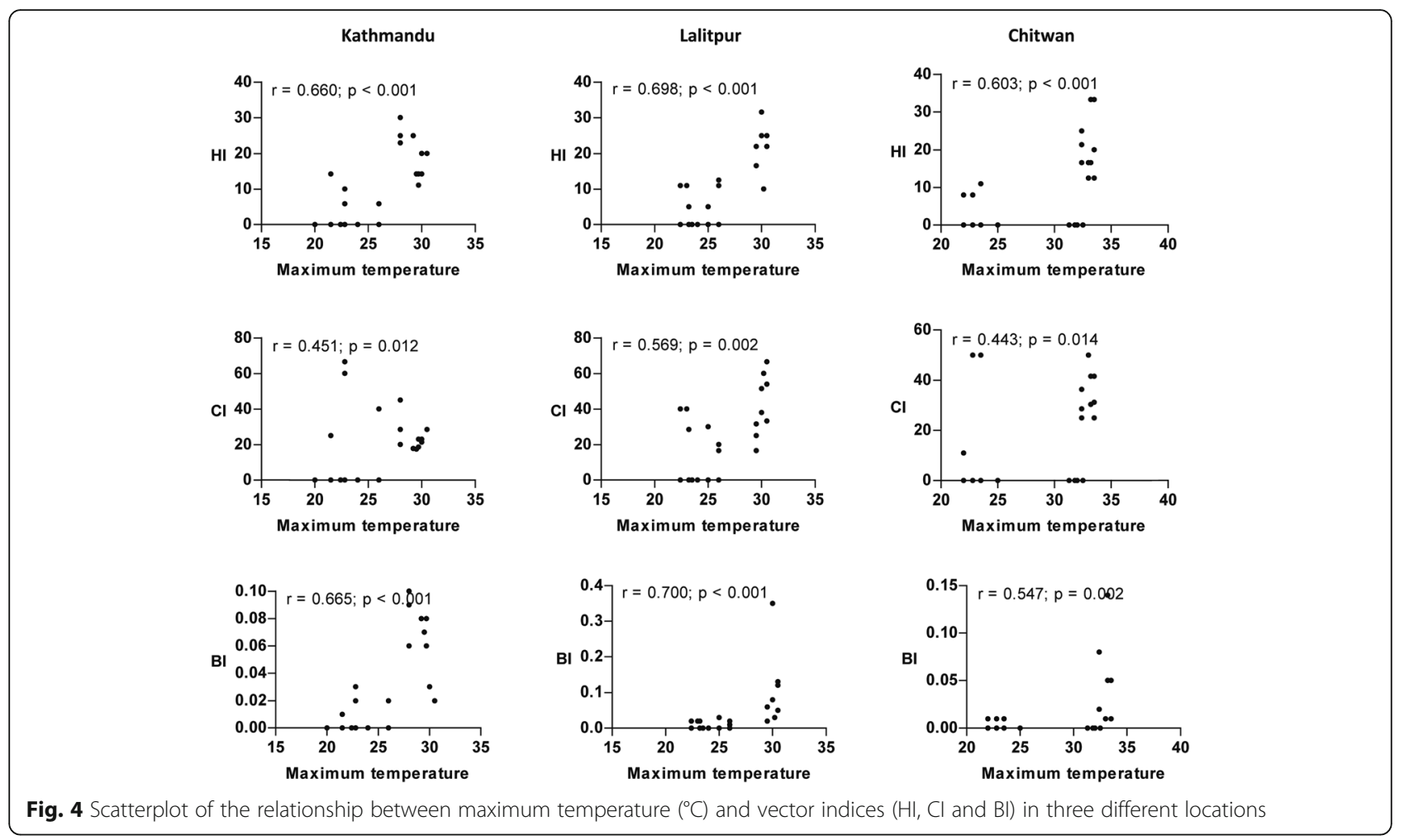

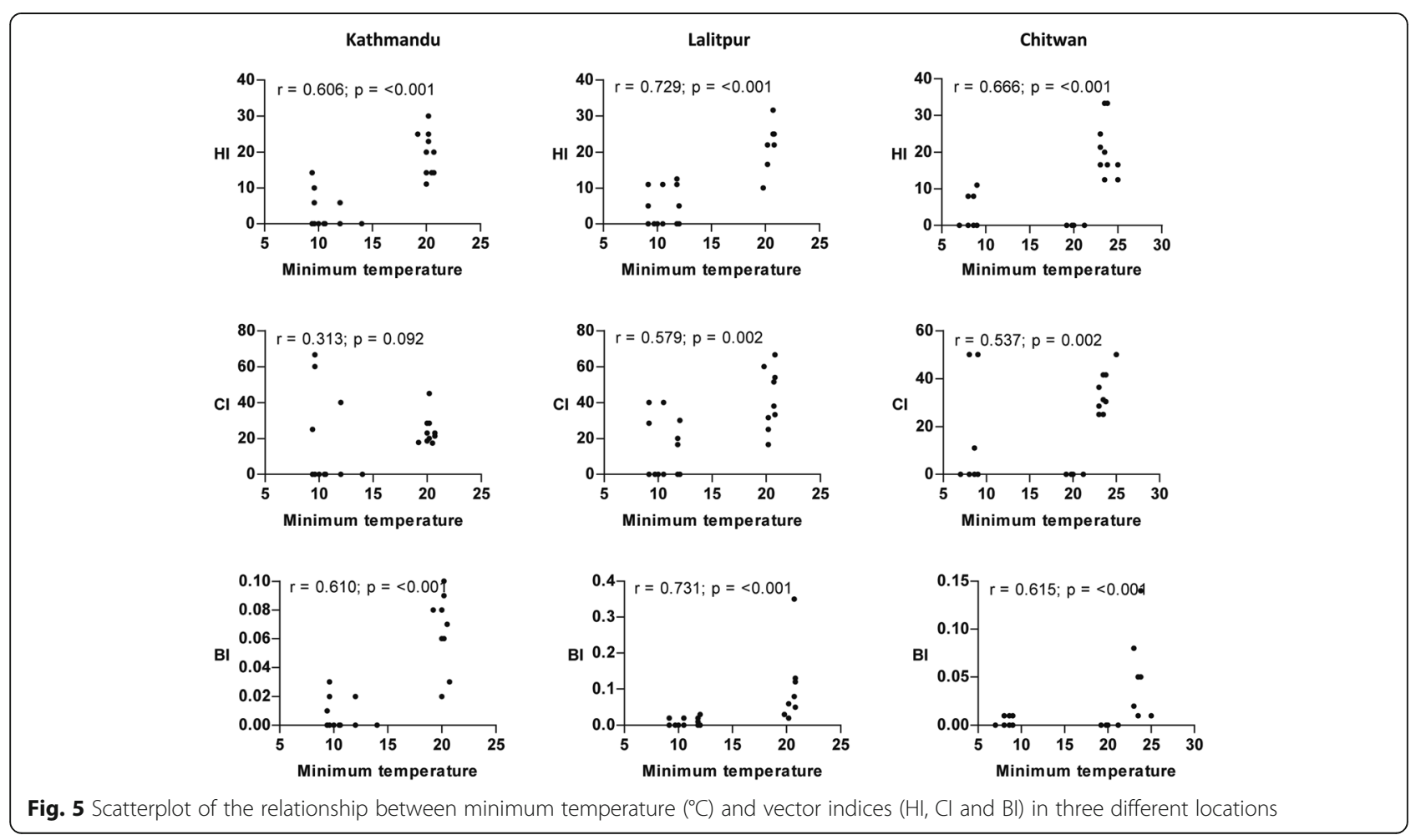




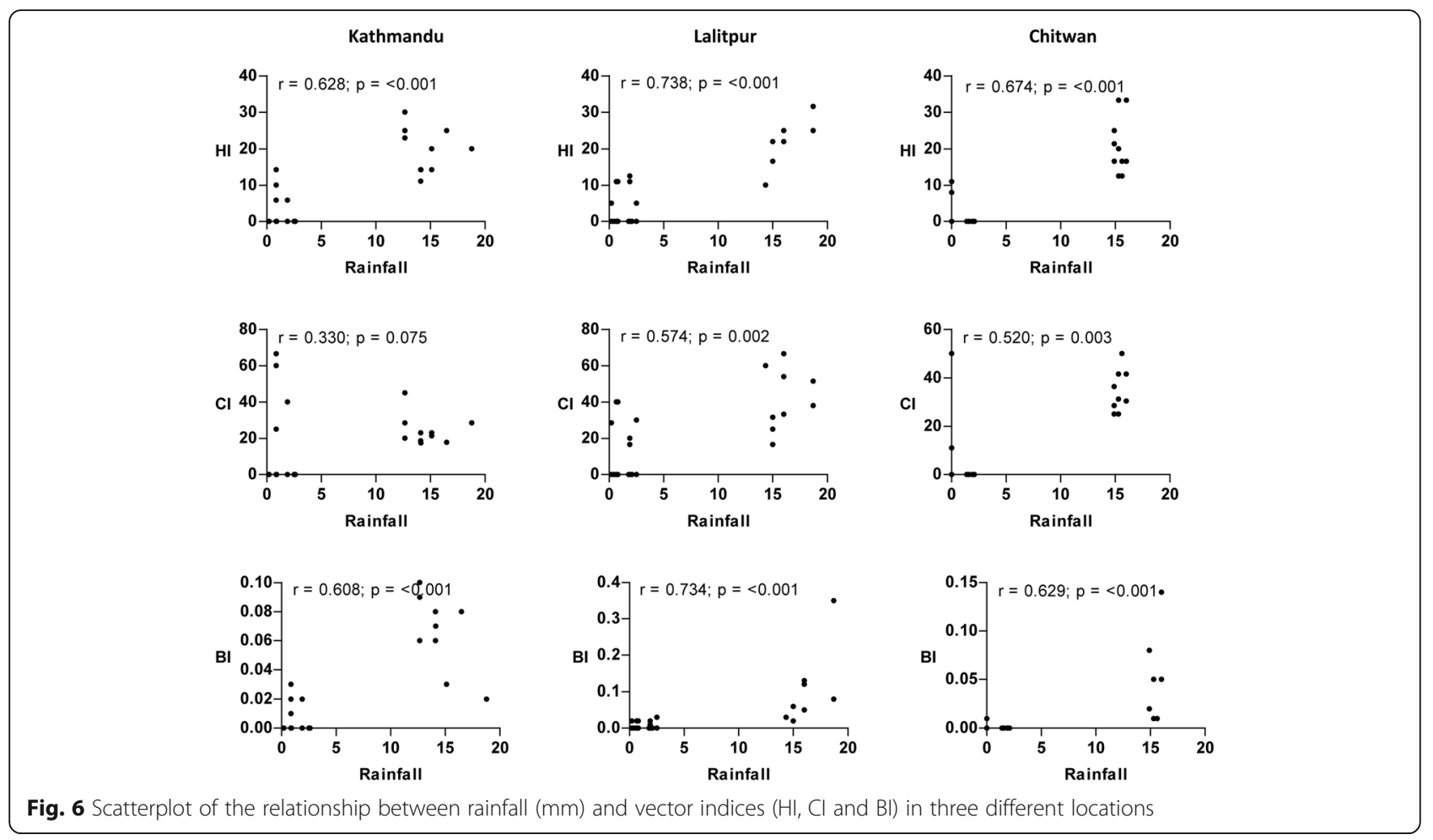

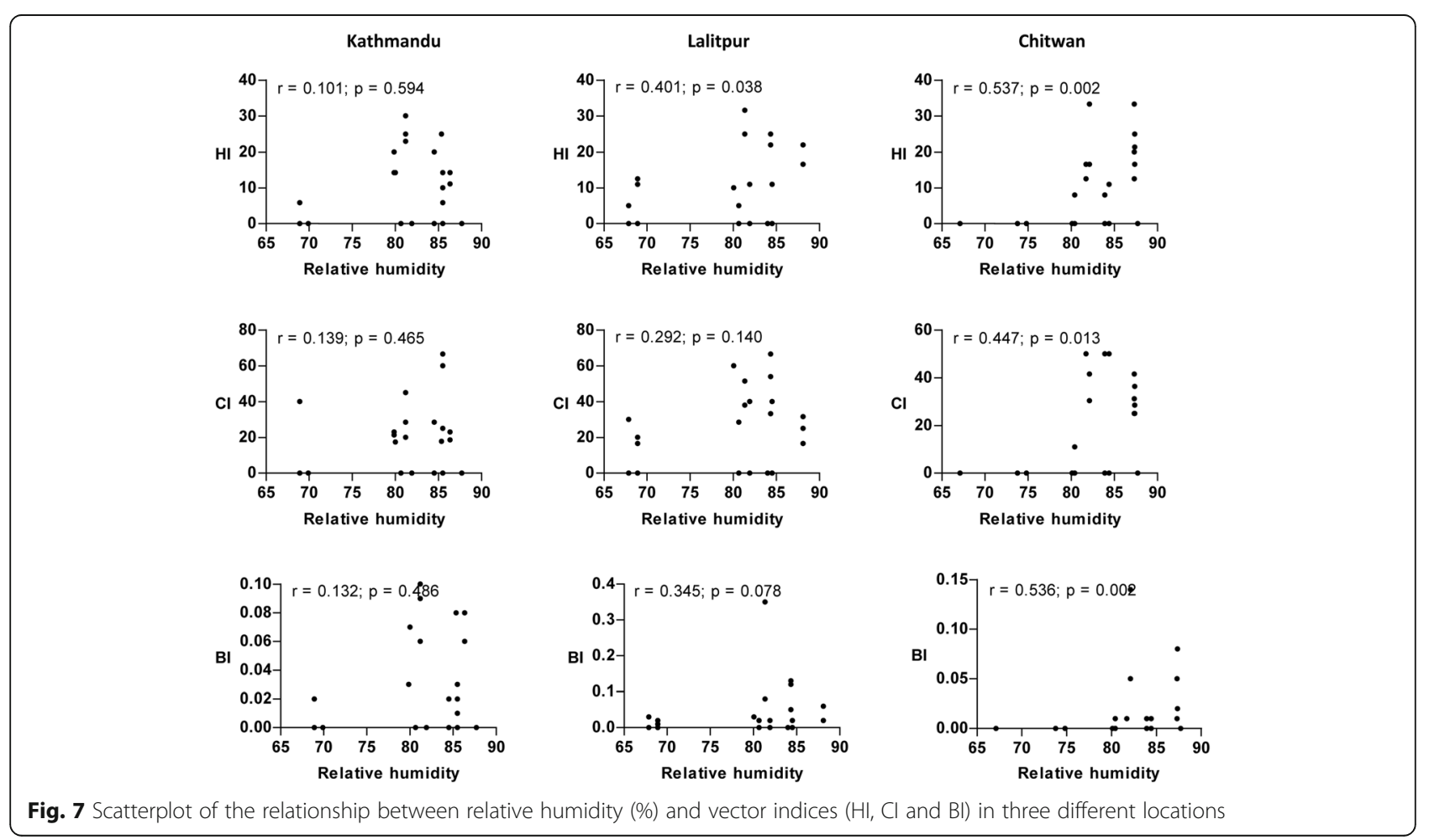




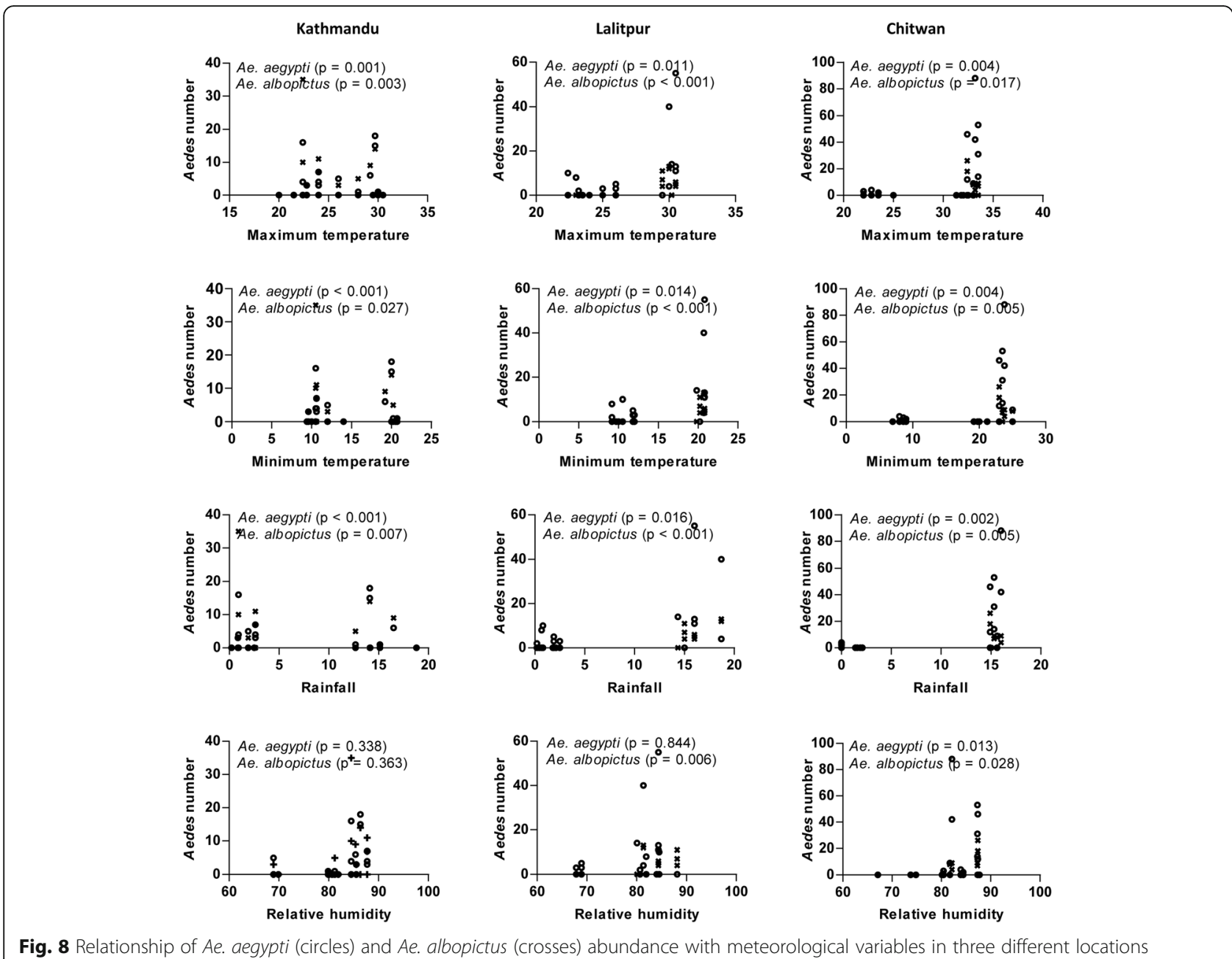

Table 3 Gamma regression models of $\mathrm{HI}_{-} 1$

\begin{tabular}{|c|c|c|c|c|c|c|c|c|}
\hline \multirow[t]{2}{*}{ Parameter } & \multicolumn{2}{|l|}{ Model 4} & \multicolumn{2}{|l|}{ Model 7} & \multicolumn{2}{|l|}{ Model 8} & \multicolumn{2}{|l|}{ Model 9} \\
\hline & b (SE) & $p^{a}$ & b (SE) & $P^{a}$ & b (SE) & $P^{a}$ & b (SE) & $P^{a}$ \\
\hline (Intercept) & $0.579(0.384)$ & 0.132 & $0.329(0.251)$ & 0.190 & $1.995(0.116)$ & $<0.0001$ & $1.825(0.099)$ & $<0.0001$ \\
\hline Chitwan & $-0.470(0.326)$ & 0.150 & & & $-0.637(0.198)$ & 0.001 & & \\
\hline Kathmandu & $-0.279(0.223)$ & 0.211 & & & & & & \\
\hline Monsoon & $2.818(0.996)$ & 0.005 & $2.90(0.374)$ & $<0.0001$ & & & & \\
\hline Post-monsoon & $1.201(0.559)$ & 0.032 & $1.148(0.361)$ & 0.001 & & & & \\
\hline TempRain & $0.143(0.67)$ & 0.831 & & & $0.734(0.094)$ & $<0.0001$ & $0.900(0.121)$ & $<0.0001$ \\
\hline RelHumidity & $-0.540(0.211)$ & 0.010 & $-0.542(0.192)$ & 0.005 & $0.340(0.116)$ & 0.003 & & \\
\hline C_TempRain & $-0.096(0.269)$ & 0.721 & & & & & $-0.429(0.202)$ & 0.034 \\
\hline C_RelHumidity & $0.619(0.304)$ & 0.042 & $0.603(0.213)$ & 0.005 & $0.749(0.207)$ & $<0.0001$ & $1.041(0.203)$ & $<0.0001$ \\
\hline K_TempRain & $-0.158(0.257)$ & 0.538 & & & & & & \\
\hline K_RelHumidity & $0.391(0.208)$ & 0.060 & $0.394(0.196)$ & 0.044 & & & $0.569(0.108)$ & 0.001 \\
\hline
\end{tabular}


all other predictors constant. TempRain $[\exp (0.143)=$ 1.15], C_RelHumidity $[\exp (0.619)=1.857]$ and K_RelHumidity $[\exp (0.391)=1.478]$ showed a greater impact on HI_1 keeping all other predictors constant. Monsoon $[\exp (2.818)=16.74]$ and post-monsoon [exp $(1.201)=3.32]$ showed a significant effect on HI_1. Monsoon showed a greater impact on HI_1 compared to post-monsoon and pre-monsoon.

Models 7 and 8 used the subsets of the 10 predictor variables. So, the inclusion of some predictors may result in a variation of the sign and value of the coefficients of the predictors due to the capacity of influence of the predictors on the response variable in a model. Model 7 included five significant predictors: monsoon, post-monsoon, RelHumidity, C_ RelHumidity and K_ RelHumidity. This model excluded TempRain or its interaction terms with location. In the partial coefficients, monsoon demonstrated a value of 2.90 or [exp $(2.90)=18.17]$ and post-monsoon 1.148 or [ $\exp (1.148)$ $=3.15]$. These two seasons seemed to have a different impact on HI_1. Relatively, HI_1 is likely to increase in the monsoon rather than in the post-monsoon season. The partial regression coefficients of RelHumidity, C_RelHumidity and K_RelHumidity were -0.542 or [exp $(-0.542)=0.582], 0.603$ or $[\exp (0.603)=1.828]$ and 0.394 or $[\exp (0.394)=1.483]$, respectively. The effect of relative humidity on HI_1 was greater in Chitwan than in Kathmandu with reference to effect in Lalitpur.

Model 8 included four significant predictors, Chitwan, TempRain, RelHumidity and C_RelHumidity, but excluded season. The partial regression coefficient for Chitwan was -0.637 or $[\exp (-0.637)=0.529]$. Chitwan showed significantly lower effect on HI_1 with reference to Lalitpur on average. TempRain showed a partial regression coefficient of 0.734 or $[\exp (0.734)=2.083$ ], followed by RelHumidity of 0.340 or $[\exp (0.340)=$ 1.40], C_RelHumidity of 0.749 or [exp $(0.749)=2.115$ ] The effect of relative humidity on HI_1 was greater in Chitwan with reference to effect in Lalitpur. The effect was followed by TempRain on HI_1 on average keeping the effect of other predictors constant. Similarly, model 9 also included four significant predictors, TempRain, C_TempRain, RelHumidity, C_RelHumidity and K_RelHumidity, with season excluded. The partial regression coefficient for TempRain was 0.900 or [exp $(0.900)=2.46]$, followed by C_TempRain of -0.429 or $[\exp (-0.429)=0.651], C_{-}$RelHumidity of 1.041 or $[\exp$ $(1.041)=2.832]$ and K_RelHumidity of 0.569 or [exp $(0.569)=1.766]$. The effect of relative humidity on HI_1 was greater in Chitwan again. TempRain had relatively lower effect on HI_1 in Chitwan compared to relative humidity at the same location with reference to Lalitpur on average after keeping the effect of other predictors constant.
For GLM regression of CI_1, model 12 was selected based on the lowest AIC value among the first five models (Additional file 4: Table S4). Following the modification of Gamma with log link function, model 15 was selected as final model (Table 4). However, this model showed a slightly higher dispersion parameter (i.e. > 1). It was selected for including only significant predictor variables.

Only four predictor variables out of 10 were highly significant predictors in model 12 under the Wald Chi-square test $(P<0.05)$. Thus, it did not meet the requirement of only significant predictors from fitting of gamma regression of CI_1 with log link function. In an attempt to interpret the coefficients of the predictors, dummy variables Chitwan and post-monsoon were significant but Kathmandu and monsoon were not significant. TempRain as a main effect and C_TempRain, K_TempRain and $\mathrm{K}_{-}$RelHumidity as interaction effects were not significant. However, RelHumidity and $\mathrm{C}_{-}$ RelHumidity were significant as main and interaction effects on CI_1 (Table 4). The coefficients when interpreted in exponential form, i.e. [exp $\left.\left(b_{i}\right)\right]$, both had a value $<1$ with reference to Lalitpur: Chitwan [exp $(-0.932)=0.394]$ and Kathmandu $[\exp (-0.151)=0.859]$. This means CI_1 had more influence in Lalitpur on average. Moreover, RelHumidity [exp $(-0.838)=0.433$, C_TempRain $[\exp (-0.317)=0.728]$ and K_TempRain $[\exp (-0.563)=0.569]$ showed significantly lower effect on CI_1 while keeping all other predictors constant. TempRain [exp $(0.868)=2.38]$, C_RelHumidity $[\exp$ $(1.173)=3.23]$ and K_RelHumidity $[\exp (0.227)=1.25]$ showed greater impact on CI_1 while keeping all other predictors constant. Monsoon [exp $(2.388)=10.89]$ and post-monsoon $[\exp (2.755)=15.72]$ showed significantly greater effect on CI_1. Post-monsoon showed a greater impact on CI_1 compared to monsoon with reference to

Table 4 Gamma regression models of Cl_1

\begin{tabular}{|c|c|c|c|c|}
\hline \multirow[t]{2}{*}{ Parameter } & \multicolumn{2}{|l|}{ Model 12} & \multicolumn{2}{|l|}{ Model 15} \\
\hline & $b(S E)$ & $P^{a}$ & b (SE) & $p^{a}$ \\
\hline (Intercept) & $1.068(0.598)$ & 0.074 & $0.904(0.358)$ & 0.012 \\
\hline Chitwan & $-0.932(0.486)$ & 0.055 & $-0.618(0.257)$ & 0.016 \\
\hline Kathmandu & $-0.151(0.319)$ & 0.637 & & \\
\hline Monsoon & $2.388(1.552)$ & 0.124 & $3.091(0.519)$ & $<0.0001$ \\
\hline Post-monsoon & $2.755(0.776)$ & $<0.0001$ & $2.817(0.523)$ & $<0.0001$ \\
\hline TempRain & $0.868(1.012)$ & 0.391 & & \\
\hline RelHumidity & $-0.838(0.303)$ & 0.006 & $-0.658(0.229)$ & 0.004 \\
\hline C_TempRain & $-0.317(0.385)$ & 0.409 & & \\
\hline C_RelHumidity & $1.173(0.451)$ & 0.009 & $0.823(0.263)$ & 0.002 \\
\hline K_TempRain & $-0.563(0.376)$ & 0.134 & & \\
\hline K_RelHumidity & $0.227(0.163)$ & 0.441 & & \\
\hline
\end{tabular}

Abbreviation: SE standard error

${ }^{a}$ Wald Chi-square test 
pre-monsoon while keeping all other predictors constant.

Model 15 included five significant predictors: Chitwan, monsoon, post-monsoon, RelHumidity and C_RelHumidity. The partial regression coefficients of Chitwan, monsoon, post-monsoon, RelHumidity and C_RelHumidity were -0.618 or $[\exp (-0.618)=0.539], 3.091$ or $[\exp (3.091)=21.99], 2.817$ or $[\exp (2.817)=16.73]$ and -0.658 or $[\exp (-0.658)=0.52]$ and 0.823 or $[\exp (0.823)$ $=2.27]$, respectively. The effect of monsoon was greatest followed by post-monsoon on CI_1 in average. C_RelHumidity had relatively more effect on CI_1 in Chitwan with reference to Lalitpur.

Similarly, for BI_1 in model 19, Gamma with log link function was selected as it possessed the lowest AIC value (-327.90) among the first six models (Additional file 4: Table S5). Gamma regression with log link function was modified as earlier. The final model selected was model 22 (Additional file 4: Table S5 and Table 5). Although model 19 included all 10 predictor variables, the fitting of the models showed only four predictors as highly significant under the Wald Chi-square test $(P<0.05)$. Thus, it did not meet the requirement of only significant predictors from the fitting of Gamma regression of BI_1 with log link function. Regarding the coefficients of the predictors, effect of Chitwan was significant but Kathmandu, monsoon and post-monsoon were not significant. TempRain as main effect, $C_{-}$TempRain and $\mathrm{K}_{-}$TempRain as interaction effects have significant consequence, but RelHumidity, C_ RelHumidity and $\mathrm{K}_{-}$RelHumidity as main and interaction effects were not significant on BI_1. The coefficients were interpreted in the exponential form, i.e. $\left[\exp \left(b_{i}\right)\right]$ as earlier. Chitwan $[\exp (0.028)=1.028]$ had a value $>1$ but Kathmandu $[\exp (-0.014)=0.986]$ had a value $<1$,

Table 5 Gamma regression models of BI_1

\begin{tabular}{|c|c|c|c|c|}
\hline \multirow[t]{2}{*}{ Parameter } & \multicolumn{2}{|l|}{ Model 19} & \multicolumn{2}{|l|}{ Model 22} \\
\hline & b (SE) & $P^{a}$ & $\overline{b(S E)}$ & $p^{a}$ \\
\hline (Intercept) & $0.210(0.0145)$ & 0.154 & $0.021(0.0083)$ & 0.011 \\
\hline Chitwan & $-0.028(0.0128)$ & 0.026 & $-0.021(0.0144)$ & 0.019 \\
\hline Kathmandu & $-0.014(0087)$ & 0.109 & $-0.016(0.0084)$ & 0.051 \\
\hline Monsoon & $0.036(0.365)$ & 0.323 & $0.054(0.0144)$ & $<0.0001$ \\
\hline Post-monsoon & $0.025(0.0202)$ & 0.214 & & \\
\hline TempRain & $0.042(0.0245)$ & 0.089 & $0.021(0.010)$ & 0.035 \\
\hline RelHumidity & $-0.005(0.0081)$ & 0.554 & & \\
\hline C_TempRain & $-0.029(0.0102)$ & 0.004 & $-0.024(0.0089)$ & 0.007 \\
\hline C_RelHumidity & $0.006(0.0119)$ & 0.615 & & \\
\hline K_TempRain & $-0.023(0.0098)$ & 0.017 & $-0.022(0.0094)$ & 0.021 \\
\hline K_RelHumidity & $0.005(0.0087)$ & 0.593 & & \\
\hline
\end{tabular}

Abbreviation: SE standard error

aWald Chi-square test indicating that BI_1 had more influence in Chitwan than in Kathmandu with reference to Lalitpur on average. RelHumidity [exp $(-0.005)=0.995]$, C_TempRain $[\exp$ $(-0.029)=0.908]$ and $K \_$TempRain $[\exp (-0.023)=0.977]$ all showed significantly lower effect on BI_1 keeping all other predictors constant. TempRain $[\exp (0.042)=$ 1.04], C_RelHumidity $[\exp (0.006)=1.006]$ and K_RelHumidity $[\exp (0.005)=1.005]$ showed greater impact on the BI_1 keeping predictors constant. Similarly, monsoon $[\exp (0.036)=1.037]$ and post-monsoon $[\exp$ $(0.025)=1.025]$ showed significant effect on BI_1. Monsoon showed a greater impact on BI_1 compared to post-monsoon with reference to pre-monsoon keeping all other predictors constant.

Six significant predictors included in model 22 were Chitwan, Kathmandu, monsoon, TempRain, C_TempRain and K_TempRain. Partial regression coefficients of Chitwan, Kathmandu, monsoon, TempRain, C_TempRain and K_TempRain were -0.021 or $[\exp (-0.021)=$ $0.979],-0.016$ or $[\exp (-0.016)=0.984], 0.054$ or $[\exp$ $(0.054)=1.055], 0.021$ or $[\exp (0.021)=1.021],-0.024$ or $[\exp (-0.024)=0.976]$ and -0.022 or $[\exp (-0.022)=$ $0.978]$, respectively. There was a greater effect of monsoon and TempRain on BI_1 in average. TempRain had a slightly greater effect on BI_1 in Kathmandu than in Chitwan with reference to Lalitpur.

Four significant predictors were included in regression models for Ae. aegypti abundance and two for Ae. albopictus abundance (Table 6). The partial regression coefficients of significant predictors monsoon, post-monsoon, RelHumidity and C_RelHumidity for Ae. aegypti abundance were 5.723 or $[\exp (5.723)=305.821], 3.378$ or $[\exp$ $(3.378)=29.31],-1.271$ or $[\exp (-1.271)=0.280]$ and 1.218 or $[\exp (1.218)=3.380]$, respectively. Similarly, the partial regression coefficients of predictors TempRain and RelHumidity for Ae. albopictus number were 1.334 or $[\exp (1.334)=3.796]$ and 1.494 or $[\exp (1.494)=4.454]$, respectively. The effect of monsoon was greater than post-monsoon with reference to pre-monsoon on $A e$. aegypti and RelHumdity had a greater influence on Ae. albopictus abundance than TempRain.

\section{Discussion}

The seasonal prevalence of dengue vectors with respect to their breeding habitats and the influence of meteorological variables on vector indices and population abundance were considered in this study. We found that potential breeding containers as well as containers positive for Aedes vectors were greater in number during monsoon season.

Consistent with earlier studies, our findings revealed that discarded tires were highest in number among the positive containers identified for Aedes spp. larval breeding [29]. An increase in vehicle numbers due to rapid expansion of urban areas in Nepal has augmented the 
Table 6 Negative binomial regression model for Ae. aegypti and Ae. albopictus number

\begin{tabular}{|c|c|c|c|c|c|c|c|c|}
\hline \multirow[t]{3}{*}{ Parameter } & \multicolumn{4}{|l|}{ Ae. aegypti } & \multicolumn{4}{|l|}{ Ae. albopictus } \\
\hline & \multicolumn{2}{|l|}{ Model 23} & \multicolumn{2}{|l|}{ Model 24} & \multicolumn{2}{|l|}{ Model 25} & \multicolumn{2}{|l|}{ Model 26} \\
\hline & $\mathrm{b}(\mathrm{SE})$ & $P^{a}$ & $\mathrm{~b}(\mathrm{SE})$ & $P^{a}$ & $\mathrm{~b}(\mathrm{SE})$ & $P^{a}$ & $\mathrm{~b}(\mathrm{SE})$ & $P^{a}$ \\
\hline (Intercept) & $-2.241(1.302)$ & 0.085 & $-2.499(1.171)$ & 0.033 & $-3.864(1.602)$ & 0.016 & $-0.447(0.277)$ & 0.107 \\
\hline Chitwan & $-1.863(0.929)$ & 0.045 & & & $0.571(0.918)$ & 0.534 & & \\
\hline Kathmandu & $-0.982(0.623)$ & 0.115 & & & & & & \\
\hline Monsoon & $3.781(2.857)$ & 0.186 & $5.723(1.586)$ & $<0.0001$ & $6.852(3.432)$ & 0.046 & & \\
\hline Post-monsoon & $6.25(2.903)$ & 0.031 & $3.378(1.611)$ & 0.036 & $1.125(1.596)$ & 0.481 & & \\
\hline TempRain & $2.158(2.186)$ & 0.323 & & & $-0.513(1.839)$ & 0.780 & $1.334(0.212)$ & $<0.0001$ \\
\hline RelHumidity & $-2.008(0.915)$ & 0.028 & $-1.271(0.722)$ & 0.078 & $-0.447(0.781)$ & 0.567 & $1.494(0.352)$ & $<0.0001$ \\
\hline C_TempRain & $0.036(0.635)$ & 0.954 & & & $-0.654(0.663)$ & 0.324 & & \\
\hline C_RelHumidity & $2.551(1.160)$ & 0.028 & $1.218(0.633)$ & 0.054 & $0.763(1.060)$ & 0.472 & & \\
\hline K_TempRain & $-0.072(0.535)$ & 0.893 & & & $-0.854(0.699)$ & 0.222 & & \\
\hline K_RelHumidity & $1.118(0.698)$ & 0.109 & & & $1.055(0.819)$ & 0.198 & & \\
\hline
\end{tabular}

number of vehicle workshops and tire recycling centers. The reckless dumping of tires in urban areas poses a major problem since they tend to be an ideal breeding habitat for Aedes spp. larvae. Discarded tires were also found to be an efficient breeding habitat for Aedes spp. by other studies [26, 30-32]. Tires are more likely to retain collected water since they are less likely to be disturbed by human activities. In addition, Aedes spp. larvae were also detected in containers made of metal and plastic. Other studies have shown that these types of containers are common breeding habitats $[26,33]$ and some have noted plastic containers as the most productive breeding habitat $[33,34]$.

Despite the fact that discarded tires were abundant in terms of the number of breeding containers, their BPR value was not the highest in this study, contrary to the findings of an earlier study in Chitwan District that demonstrated the highest BPR value for discarded tires [29]. Glass container in Kathmandu had the highest BPR value. However, this is due to the fact that the sole water-holding glass container identified was infested with Aedes larvae. Similarly, the ratio of metal containers positive for Aedes larvae to the total number of water-holding metal containers was higher compared to that of discarded tires in Lalitpur. This made the BPR value of metal containers higher than that of discarded tires, despite a greater number of discarded tires being identified. Similarly, BPR value of metal drum container was highest in Chitwan. These results show that metal and glass containers are suitable breeding habitats for Aedes spp. and therefore, these containers should be monitored with equal priority during vector surveillance.

We also found that monsoon season showed the highest values for $\mathrm{HI}, \mathrm{CI}, \mathrm{BI}$ and vector abundance. In the studies conducted in Indonesia, Vietnam, South Korea and Myanmar, higher $\mathrm{HI}, \mathrm{BI}$ and vector population were found during the rainy season rather than dry season [35-38]. HI, CI and BI are the commonly used larval indices in determining the general distribution and principal habitats of Aedes vectors, with $\mathrm{HI}$ and $\mathrm{BI}$ being the most widely used indices in the monitoring of dengue vector populations [39]. Although these indices have direct relevance to the dynamics of disease transmission, the threshold levels of vector infestation that trigger dengue transmission is influenced by several factors, such as mosquito longevity and immunological status of the human population [26]. Three different risks of HI, with $<0.1 \%$ considered as low, $0.1-5 \%$ as medium and $>$ $5 \%$ as high, were proposed by the Pan American Health Organization to prevent dengue transmission [40, 41]. Our study shows that HI values in all the three surveyed locations fall under high risk and medium risk during monsoon and post-monsoon, respectively. The nil value of $\mathrm{HI}$ in dengue endemic Chitwan during pre-monsoon indicates low risk but these values in non-endemic Kathmandu and Lalitpur indicate medium risk. Thus, HI cannot be a reliable predictor of dengue. Although there is no universal critical threshold, an arbitrary threshold of $\mathrm{BI}=5$ has been applied and the prediction accuracy of dengue epidemic at BI > 5 was $77 \%$ [40]. Dengue transmission has been observed with a vector density below the threshold in another study [25]. The BI values in our study were less than $5 \%$. As suggested by other researchers, BI cannot, however, be used as a sole predictor of dengue epidemics $[3,40]$ although Tun-Lin et al. [42] demonstrated that BI can be considered as the best indicator compared to other indices. 
The fact that the greatest numbers of larvae were found during monsoon in this study is linked to the low variation in the temperature range during this season. As shown by the meteorological data for Nepal, the variation in the temperature range (indicated by the standard deviation in Table 1) and difference between maximum and minimum temperature is lower during monsoon compared to other seasons, which can be linked to finding a greater number of Aedes spp. larvae during monsoon in this study (Additional file 2: Figure S1). A greater difference between daily maximum and minimum temperature has been attributed to reduced larval survival and increased development time [43]. A previous study in Nepal by Dhimal et al. [14] showed a greater number of adult Ae. aegypti and Ae. albopictus towards the end of monsoon and post-monsoon season.

Although the adult female population has been shown to peak in November [11], our study found the maximum number of larvae during monsoon. The reason could be that an increase in the number of water-holding containers during monsoon season created sufficient breeding habitats for Aedes larvae, resulting in the vector larval stages being dominant. Subsequently, a decline in the number of water-holding containers in post-monsoon season reduced the population of larvae. However, the peak population of adults as observed by Dhimal et al. [11] could be due to the emerged larvae thriving during post-monsoon.

According to a study conducted in Indonesia [38], fewer mosquito larvae were found in the dry season compared to the wet season. Less rainfall means a reduced amount of water retained in containers which affects mosquito breeding. Similarly, the population of $A e$. aegypti observed by another study was found to be the highest during the period of high rainfall [44]. However, heavy and continuous rainfall has been linked to a reduction in adult mosquito population due to the washing away of immature stages of mosquitoes [45, 46]. Another study found that moderate rain with ideal temperature enhances the Ae aegypti population [33]. Aedes abundance has been regulated by temperature rather than by precipitation $[47,48]$.

In this study, we found the mean Ae. aegypti population abundance to be higher in the lowland than in the upland regions while the mean Ae. albopictus population abundance was almost identical in both ecological regions (Fig. 3). Chitwan, representing lowland region in this study, is considered a dengue endemic region of Nepal. A higher number of Ae. aegypti in the lowland region implies that the abundance of this primary vector is an indicator of risk for dengue transmission; $A e$. aegypti is known to be the most effective vector for dengue viruses [49]. Similarly, Wijayanti et al. [38] considered a high level of adult Ae. aegypti in endemic and sporadic areas as a potential indicator of dengue virus transmission risk in Indonesia. Larval density has been shown to be related to sporadic dengue and its outbreaks in Guangzhou, China [50].

Overall, we found a higher population abundance of Ae. aegypti than Ae. albopictus in this study (Additional file 2: Figure S1). Since the entomological survey was carried out in urban areas with only man-made containers identified, we were more likely to find a greater number of Ae. aegypti since they prefer urban areas [38] while Ae. albopictus favor sub-urban areas and natural containers $[38,51]$. During this study, we found larvae of both Ae. aegypti and Ae. albopictus breeding in the same habitat in some of the containers. It has been reported that coexistence of both vectors is possible when a warmer and drier climate alleviates competition from Ae. albopictus [52]. Thus, a rise in temperature can facilitate the expansion of Ae. aegypti populations.

Meteorological variables are considered some of the environmental factors for increased risk of dengue since they influence the viral replication and vector dynamics. For example, higher temperature has been associated with accelerated virus replication and its reduced extrinsic incubation period in the vector [21, 53]. In addition, elevated temperatures increase mosquito development and host biting rates $[18,54]$. However, the increased temperature should be within the optimum range and exceeding this range will result in decreased abundance and reduced survival probabilities [55].

The strength of the relation of meteorological variables with vector indices may be inferred from correlation analysis, but their association is elucidated only by regression analysis. The models that include maximum numbers of significant predictors in our regression analysis were selected for interpretation. The overall effect of the meteorological factor TempRain was found to be significant on vector indices HI_1 and BI_1 compared to relative humidity in the regression analysis. The higher significant effect of temperature and rainfall in the upland region was obvious from the analysis. The temperature in upland is lower compared to lowland. A lower effect of temperature fluctuation on mortality rate of Ae. aegypti and Ae. albopictus had been demonstrated within the temperature range of $20-30{ }^{\circ} \mathrm{C}$ [56]. This temperature range is closer to the temperature records in lowland Chitwan rather than in the upland Kathmandu Valley. Thus, a change in temperature in the uplands will have a greater influence on the mortality rate than in the lowland. Rainfall can potentially make abundant water-holding containers available, resulting in more houses with vector-infested containers. This can be attributed to the increased number of vectors in the monsoon season which showed a significantly higher effect on HI_1 and BI_1 compared to other seasons. 
However, an increase in the amount of rainfall may not always be favorable for vector abundance $[45,46]$. A longer period of moderate rain is important to facilitate the availability of vector breeding sites.

Considering location as predictor variable, Lalitpur had a greater effect on HI_1 compared to Kathmandu and Chitwan. Despite sharing an identical climate pattern, the discrepancy in the effect of Kathmandu and Lalitpur on this response variable can be linked to the effect of non-meteorological factors, which is a limitation of this study. CI showed the weakest relationship of all the entomological indices since it indicated only the proportion of infested containers and not per house or per area [23]. Unlike the number of houses, the number of containers within a locality will not be same throughout the year. Furthermore, some of the containers may be located temporarily, thus, $\mathrm{CI}$ cannot reflect the true figure of entomological index in relation to variation of climate in different seasons. We observed that BI had more influence in Chitwan compared to Kathmandu. In the light of Chitwan being an endemic region for dengue transmission, BI should be considered to study the relation of vector indices and dengue incidence.

In terms of location, the effect of relative humidity was greater in Chitwan than Kathmandu. Relative humidity affects the evaporation of water with a higher rate at hotter temperatures [57]. This implies that the influence of relative humidity on vector indices and number is likely to be higher in warmer Chitwan. Relative humidity is one of the crucial factors in the life-cycle of mosquitoes [58]. Higher levels of moisture stimulate the survival of Aedes larvae and induce eclosion [59]. Although temperature and rainfall have been frequently addressed factors for vector abundance and dengue transmission, researchers have also considered relative humidity as a contributing factor [17, $60]$. The influence of relative humidity on vector indices was greater than temperature-rainfall in the lowland region. The geographical location, the large Narayani River and the proximity of dense tropical forest in lowland Chitwan is likely to contribute to the rise in humidity.

The data on vector indices do not reflect the population count of vector since house or container infested with even a single vector is considered as positive. Hence, we analyzed the effect of predictor variables on Ae. aegypti and Ae. albopictus abundance and found that the influences are not identical. Other researchers have found that the effects of temperature and relative humidity were not same for Ae. aegypti and Ae. albopictus [52, 61]. The effect of RelHumidity was higher on Ae. albopictus. Aedes aegypti benefitted with higher survival as it is less influenced by humidity compared to Ae. albopictus [57].

Any change in climate resulting in the range of meteorological variables conducive for vector breeding is expected to trigger an increase in vector population and thereby affect dengue transmission. However, the effect of climatic factors on dengue transmission and vector distribution is not consistent throughout the world [17, 18, 62, 63]. Ecological and human factors are essential in driving vector-borne diseases [64]. Socio-economic condition, population, water storage behaviors and strength of vector surveillance are also essential considerations for vector prevalence. Rapid urbanization, an increase in international trade and frequent travel have been involved in the spread of vectors and, therefore, increased the global risk of dengue transmission $[17,65,66]$. Thus, vector control is crucial for the containment of dengue transmission. Intending a timely response to dengue outbreaks, the Government of Nepal has adopted a vector control programme which focuses on the search and destruction of Aedes spp. larvae during an outbreak. A few locals of Chitwan have volunteered in vector control at the time of outbreaks. In the light of the fact that dengue cases reach its peak during the month of October in Nepal, the vector control programmes are implemented during the post-monsoon season. The prevalence of Aedes larvae in monsoon and the more significant effect of monsoon season on HI_1, CI_1, BI_1 and Ae. aegypti abundance revealed in this study suggest that the existing practice of vector control during the time of outbreaks may not be sufficient for the effective management of vectors. Executing intensive vector control programme from the onset of a monsoon season with the involvement of a community is fundamental to thwarting off the potential dengue epidemics in the country.

\section{Conclusions}

Our study determined that Aedes larval populations peak during the monsoon season when water-holding containers are abundant. Temperature and rainfall contribute to vector indices in upland hilly region whereas relative humidity in lowland plains. The effect of meteorological variables on vector abundance can differ among geographical locations with diverse climate conditions. However, vector dynamics and dengue transmission is complex since other contributing factors such as socio-economic, travel, trade, urbanization and public health intervention are involved. Intense vector surveillance and control measures need to be implemented in lowland Terai as well as the upland hilly regions of Nepal to prevent epidemics of dengue.

\section{Additional files}

Additional file 1: Table S1. Number of water-holding containers infested with Aedes larvae in the three different locations of the study area in different seasons. (DOCX $16 \mathrm{~kb}$ )

Additional file 2: Figure S1. Number of Aedes species collected in post-monsoon, monsoon and pre-monsoon seasons. (TIF $4144 \mathrm{~kb}$ ) 
Additional file 3: Table S2. Principal components analysis for factor extraction (rotation component matrix). (DOCX $11 \mathrm{~kb}$ )

Additional file 4: Table S3. A goodness-of-fit test for a response variable using generalized linear model (GLM) regression of HI_1. Table S4. A goodness-of-fit test for a response variable using generalized linear model (GLM) regression of CI 1. Table S5. A goodness-of-fit test for a response variable using generalized linear model (GLM) regression of BI_1. Table S6. A goodness-of-fit test for a response variable using generalized linear model (GLM) regression of Ae. aegypti numbers and Ae. albopictus numbers. (DOCX $21 \mathrm{~kb})$

\section{Abbreviations}

Bl: Breteau index; BPR: Breeding preferences ratio; Cl: Container index; DENV: Dengue virus; GLM: Generalized linear model; GLMM: Generalized linear mixed model; HI: House index; PCA: Principal components analysis

\section{Acknowledgements}

We are thankful for this research being financed under the Climate Change Research Grants Program implemented by the Nepal Academy of Science and Technology. The programme is part of the Mainstreaming Climate Change Risk Management in Development project. This project is a component of Nepal's Pilot Program for Climate Resilience and is executed by the Ministry of Population and Environment (Nepal), financed by the Climate Investment Funds, administered by the Asian Development Bank with technical assistance from ICEM, METCON and APTEC.

\section{Funding}

This study was funded by the Nepal Academy of Science and Technology/ Asian Development Bank RGP-018 provided to the first author.

\section{Availability of data and materials}

The data supporting the conclusions of this article are provided within the article and its additional files.

\section{Authors' contributions}

RT, AS and DKC conceived and designed the study. RT and IG were responsible for the fieldwork and experiments. RT, MRB and MD analyzed the data. RT, MD, AV and DKC prepared the manuscript. All authors read and approved the final manuscript.

\section{Ethics approval and consent to participate}

Ethics approval was granted by the Ethical Review Board (ERB) of the Nepal Health Research Council (reg. no. 183/2015). Permission to collect mosquitoes from households and premises was obtained from the residents.

\section{Consent for publication}

Not applicable.

\section{Competing interests}

The authors declare that they have no competing interests.

\section{Publisher's Note}

Springer Nature remains neutral with regard to jurisdictional claims in published maps and institutional affiliations.

\section{Author details}

${ }^{1}$ Central Department of Microbiology, Tribhuvan University, Kathmandu, Nepal. ${ }^{2}$ Amity Institute of Microbial Technology, Amity University, Noida, UP, India. ${ }^{3}$ Natural History Museum, Tribhuvan University, Kathmandu, Nepal. ${ }^{4}$ Nepal Health Research Council, Ministry of Health and Population, Ramshah Path, Kathmandu, Nepal.

Received: 20 July 2018 Accepted: 7 January 2019

Published online: 18 January 2019

\section{References}

1. Kyle JL, Harris E. Global spread and persistence of dengue. Annu Rev Microbiol. 2008;62:71-92
2. Bhatt $S$, Gething PW, Brady OJ, Messina JP, Farlow AW, Moyes CL, et al. The global distribution and burden of dengue. Nature. 2013;496:504-7.

3. Bowman LR, Runge-Ranzinger $S$, McCall PJ. Assessing the relationship between vector indices and dengue transmission: a systematic review of the evidence. PLoS Negl Trop Dis. 2014;8:e2848.

4. Guzman M, Harris E. Dengue. Lancet. 2015;385:453-65.

5. Pandey BD, Morita K, Khanal SR, Takasaki T, Miyazaki I, Ogawa T, et al. Dengue virus, Nepal. Emerg Infect Dis. 2008;14:514-5.

6. Pandey BD, Rai SK, Morita K, Kurane I. First case of dengue virus infection in Nepal. Nepal Med Coll J. 2004;6:157-9.

7. DoHS. Annual report 2067/68 (2010/2011). Kathmandu: Department of Health Services, Ministry of Health and Population, Government of Nepal; 2012

8. DoHS. Annual report 2071/72 (2014/2015). Kathmandu: Department of Health Services, Ministry of Health and Population, Government of Nepal; 2016

9. Pun SB. Dengue: an emerging disease in Nepal. J Nepal Med Assoc. 2011;51: 203-8.

10. Gautam I, Dhimal MN, Shrestha SR, Tamrakar AS. First record of Aedes aegypti (L.) vector of dengue virus from Kathmandu, Nepal. J Nat Hist Mus. 2009;24:156-64.

11. Dhimal M, Ahrens B, Kuch U. Species composition, seasonal occurrence, habitat preference and altitudinal distribution of malaria and other disease vectors in eastern Nepal. Parasit Vectors. 2014;7:540.

12. Dhimal M, Gautam I, Joshi HD, O'Hara RB, Ahrens B, Kuch U. Risk factors for the presence of chikungunya and dengue vectors (Aedes aegypti and Aedes albopictus), their altitudinal distribution and climatic determinants of their abundance in Central Nepal. PLoS Negl Trop Dis. 2015;9:e0003545.

13. Darsie RF, Pradhan S. The mosquitoes of Nepal: their identification, distribution and biology. Mosquito Syst. 1990;22:69-130.

14. Dhimal M, Gautam I, Kreß A, Müller R, Kuch U. Spatio-temporal distribution of dengue and lymphatic filariasis vectors along an altitudinal transect in Central Nepal. PLoS Negl Trop Dis. 2014;8:e3035.

15. Gubler DJ, Ooi EE, Vasudevan S, Farrar J. Dengue and dengue hemorrhagic fever. Wallingford: CABI; 1997.

16. Arunachalam N, Tana S, Espino F, Kittayapong P, Abeyewickreme W, Wa KT, et al. Eco-bio-social determinants of dengue vector breeding: a multicountry study in urban and periurban Asia. Bull World Health Organ. 2010;88:173-84

17. Hales S, De Wet N, Maindonald J, Woodward A. Potential effect of population and climate changes on global distribution of dengue fever: an empirical model. Lancet. 2002;360:830-4.

18. Patz JA, Martens WJM, Focks DA, Jettend TH. Dengue fever epidemic potential as projected by general circulation models of global climate change. Environ Health Perspect. 1998;106:147-53.

19. Githeko AK, Lindsay SW, Confalonieri UE, Patz JA. Climate change and vector-borne diseases: a regional analysis. Bull World Health Organ. 2000;78: 1136-47.

20. Reiter P. Climate change and mosquito-borne disease. Environ Health Perspect. 2001;109:141-61

21. Bangs MJ, Larasati RP, Corwin AL, Wuryadi S. Climatic factors associated with epidemic dengue in Palembang, Indonesia: implications of short-term meteorological events on virus transmission. Southeast Asian J Trop Med Public Health. 2006;37:1103-16

22. Ehelepola ND, Ariyaratne K, Buddhadasa WM, Ratnayake S, Wickramasinghe M. A study of the correlation between dengue and weather in Kandy City, Sri Lanka (2003-2012) and lessons learned. Infect Dis Poverty. 2015:4:42.

23. Focks DA. A review of entomological sampling methods and indicators for dengue vectors. In: UNDP/World BankWHO Special Programme for Research and Training in Tropical Diseases. Geneva: World Heath Organization; 2003. p. 16

24. Sanchez L, Cortinas J, Pelaez O, Gutierrez H, Concepción D, Van der Stuyft P. Breteau Index threshold levels indicating risk for denguetransmission in areas with low Aedes infestation. Trop Med Int Health. 2010:15:173-5.

25. Sanchez L, Vanlerberghe V, Alfonso L, Marquetti Mdel C, Guzman M, Bisset J, et al. Aedes aegypti larval indices and risk for dengue epidemics. Emerg Infect Dis. 2006;12:800-6.

26. Vijayakumar K, Sudheesh Kumar TK, Nujum ZT, Umarul F, Kuriakose A A study on container breeding mosquitoes with special reference to Aedes (Stegomyia) aegypti and Aedes albopictus in Thiruvananthapuram district India. J Vector Borne Dis. 2014;51:27-32. 
27. DHM. Final report: Study of climate and climatic variation over Nepal. Kathmandu: Department of Hydrology and Meterology, Government of Nepal; 2015. p. 16-8.

28. Kumar RR, Kamal S, Patnaik SK, Sharma RC. Breeding habitats and larval indices of Aedes aegypti (L.) in residential areas of Rajahmundry town, Andhra Pradesh. J Commun Dis. 2002;34:50-8.

29. Shrestha R, Pant ND, GC G, Thapa S, Neupane B, Shah Y, et al. Serological and entomological study of dengue in Dang and Chitwan districts of Nepal. PLoS One. 2016;11:e0147953.

30. Barrera R, Amador M, MacKay AJ. Population dynamics of Aedes aegypti and dengue as influenced by weather and human behavior in San Juan, Puerto Rico. PLoS Negl Trop Dis. 2011;5:e1378.

31. Reiter $P$, Sprenger $D$. The used tire trade: a mechanism for the worldwide dispersal of container breeding mosquitoes. J Am Mosq Control Assoc. 1987;3:494-501.

32. Rubio A, Cardo MV, Vezzani D. Tire-breeding mosquitoes of public health importance along an urbanisation gradient in Buenos Aires, Argentina. Mem Inst Oswaldo Cruz. 2011;106:678-84.

33. Jeelani S, Sabesan S. Aedes vector population dynamics and occurrence of dengue fever in relation to climate variables in Puducherry, South India. Int J Curr Microbiol App Sci. 2013;2:313-22.

34. Almanzor BL, Ho HT, Carvajal TM. Ecdysis period and rate deviations of dengue mosquito vector, Aedes aegypti reared in different artificial waterholding containers. J Vector Borne Dis. 2016;53:37-45.

35. Akram W, Lee JJ. Effect of habitat characteristics on the distribution and behavior of Aedes albopictus. J Vector Ecol. 2004;29:379-82.

36. Oo TT, Storch V, Madon MB, Becker N. Factors influencing the seasonal abundance of Aedes (Stegomyia) aegypti and the control strategy of dengue and dengue haemorrhagic fever in Thanlyin Township, Yangon City, Myanmar. Trop Biomed. 2011;28:302-11.

37. Pham HV, Doan HTM, Phan TIT, Minh NNT. Ecological factors associated with dengue fever in a central highlands Province, Vietnam. BMC Infect Dis. 2011;11:172

38. Wijayanti SPM, Sunaryo S, Suprihatin S, McFarlane M, Rainey SM, Dietrich I, et al. Dengue in Java, Indonesia: Relevance of mosquito indices as risk predictors. PLoS Negl Trop Dis. 2016;10:e0004500.

39. Chen SC, Liao CM, Chio CP, Chou HH, You SH. Lagged temperature effect with mosquito transmission potential explains dengue variability in southern Taiwan: insights from a statistical analysis. Sci Total Environ. 2010; 408:4069-75.

40. Chang F-S, Tseng Y-T, Hsu P-S, Chen C-D, Lian I-B, Chao D-Y. Re-assess vector indices threshold as an early warning tool for predicting dengue epidemic in a dengue non-endemic country. PLoS Negl Trop Dis. 2015;9: e0004043.

41. Pan American Health Organization. Dengue and dengue hemorrhagic fever in the Americas: Guidelines for prevention and control. Volume 548. Washington: Pan American Sanitary Bureau, Regional Office of the World Health Organization, Pan American Health Organization Scientific Publication; 1994

42. Tun-Lin W, Kay BH, Barnes A, Forsyth S. Critical examination of Aedes aegypti indices: correlations with abundance. Am J Trop Med Hyg. 1996;54:543-7.

43. Carrington LB, Seifert SN, Willits NH, Lambrechts L, Scott TW. Large diurnal temperature fluctuations negatively influence Aedes aegypti (Diptera: Culicidae) life-history traits. J Med Entomol. 2013;50:43-51.

44. Micieli MV, Campos RE. Oviposition activity and seasonal pattern of a population of Aedes (Stegomyia) aegypti (L.) (Diptera: Culicidae) in subtropical Argentina. Mem Inst Oswaldo Cruz. 2003;98:659-63.

45. Baruah S, Dutta P. Seasonal prevalence of Aedes aegypti in urban and industrial areas of Dibrugarh District, Assam. Trop Biomed. 2013;30:434-43.

46. Campbell KM, Lin CD, lamsirithaworn S, Scott TW. The complex relationship between weather and dengue virus transmission in Thailand. Am J Trop Med Hyg. 2013;89:1066-80.

47. Moore CG, Cline BL, Ruiz-Tibén E, Lee D, Romney-Joseph H, Rivera-Correa E. Aedes aegypti in Puerto Rico: environmental determinants of larval abundance and relation to dengue virus transmission. Am J Trop Med Hyg. 1978;27:1225-31

48. Toma T, Sakamoto S, Miyagi I. The seasonal apperance of Aedes albopictus in Okinawajima, the Ryukyu archipelago, Japan. Mosq News. 1982;42:179-83.

49. Vazeille M, Rosen L, Mousson L, Failloux AB. Low oral receptivity for dengue type 2 viruses of Aedes albopictus from Southeast Asia compared with that of Aedes aegypti. Am J Trop Med Hyg. 2003;68:203-8.
50. Luo L, Li X, Xiao X, Xu Y, Huang M, Yang Z. Identification of Aedes albopictus larval index thresholds in the transmission of dengue in Guangzhou, China. J Vector Ecol. 2015;40:240-6.

51. Higa Y. Dengue vectors and their spatial distribution. Trop Med Health. 2011;39:17-27.

52. Juliano SA, O'Meara GF, Morrill JR, Cutwa MM. Desiccation and thermal tolerance of eggs and the coexistence of competing mosquitoes. Oecologia. 2002;130:458-69.

53. Watts DM, Burke DS, Harrison BA, Whitmire RE, Nisalak A. Effect of temperature on the vector efficiency of Aedes aegypti for dengue 2 virus. Am J Trop Med Hyg. 1987:36:143-52.

54. McMichael AJ, Campbell-Lendrum DH, Corvalán CF, Ebi KL, Githeko AK, Scheraga JD, et al. Climate change and human health: risk and responses. Geneva: World Health Organization; 2003.

55. Williams C, Mincham G, Ritchie S, Viennet E, Harley D. Bionomic response of Aedes aegypti to two future climate change scenarios in far north Queensland, Australia: implications for dengue outbreaks. Parasit Vectors. 2014;7:447.

56. Brady OJ, Johansson MA, Guerra CA, Bhatt S, Golding N, Pigott DM, et al. Modelling adult Aedes aegypti and Aedes albopictus survival at different temperatures in laboratory and field settings. Parasit Vectors. 2013;6:351.

57. Schmidt CA, Comeau G, Monaghan AJ, Williamson DJ, Ernst KC. Effects of desiccation stress on adult female longevity in Aedes aegypti and Ae. albopictus (Diptera: Culicidae): results of a systematic review and pooled survival analysis. Parasit Vectors. 2018;11:267.

58. Naish S, Dale P, Mackenzie JS, McBride J, Mengersen K, Tong S. Climate change and dengue: a critical and systematic review of quantitative modelling approaches. BMC Infect Dis. 2014;14:167.

59. Luz C, Tai M, Santos A, Silva H. Impact of moisture on survival of Aedes aegypti eggs and ovicidal activity of Metarhizium anisopliae under laboratory conditions. Mem Inst Oswaldo Cruz. 2008;103:214-5.

60. Halide $H$, Ridd P. A predictive model for dengue hemorrhagic fever epidemics. Int J Environ Health Res. 2008;18:253-65.

61. Waldock J, Chandra NL, Lelieveld J, Proestos Y, Michael E, Christophides G, et al. The role of environmental variables on Aedes albopictus biology and chikungunya epidemiology. Pathog Glob Health. 2013;107:224-41.

62. Banu S, Hu W, Hurst C, Tong S. Dengue transmission in the Asia-Pacific region: impact of climate change and socio-environmental factors. Trop Med Int Health. 2011;16:598-607.

63. Russell RC, Currie BJ, Lindsay MD, Mackenzie JS, Ritchie SA, Whelan PI. Dengue and climate change in Australia: predictions for the future should incorporate knowledge from the past. Med J Aust. 2009;190:265-8.

64. Zhou SS, Huang F, Wang JJ, Zhang SS, Su YP, Tang LH. Geographical, meteorological and vectorial factors related to malaria re-emergence in Huang-Huai River of central China. Malar J. 2010;9:337.

65. Benedict MQ, Levine RS, Hawley WA, Lounibos LP. Spread of the tiger: global risk of invasion by the mosquito Aedes albopictus. Vector Borne Zoonotic Dis. 2007:7:76-85.

66. Sutherst RW. Global change and human vulnerability to vector-borne diseases. Clin Microbiol Rev. 2004;17:136-73.

\section{Ready to submit your research? Choose BMC and benefit from:}

- fast, convenient online submission

- thorough peer review by experienced researchers in your field

- rapid publication on acceptance

- support for research data, including large and complex data types

- gold Open Access which fosters wider collaboration and increased citations

- maximum visibility for your research: over $100 \mathrm{M}$ website views per year

At BMC, research is always in progress.

Learn more biomedcentral.com/submissions 